\title{
Sow $561114--11$ Autodetachment Spectroscopy of Metastable Negative Ions
}

\author{
T. J. Kvale, * R. N. Compton, $†$ and G. D. Alton
}

CONF-861114--11

DE87 000745

\section{Oak Ridge National Laboratory, Oak Ridge, Tennessee 37831-6125}

and

\author{
J. S. Thompson and D. J. Pegg $\ddagger$
}

The University of Tennessee, Knoxville, Tennessee 37996

\begin{abstract}
This paper is a review of some of our recent measurements on the metastable negative ions, $\mathrm{Be}^{-}$and $\mathrm{He}_{2}^{-}$, using the technique of fast-beam autodetachment spectroscopy.
\end{abstract}

*Present address: Department of Physics and Astronomy, The University of Toledo, Toledo, Ohio 43606.

†Also with the Department of Chemistry, The University of Tennessee, Knoxville, Tennessee 37996.

$\ddagger$ Also with the Physics Division, Oak Ridge National Laboratory, Oak Ridge, Tennessee 37831.

\section{DISCLAIMER}

By ecceptence of this erticle, the Dublisher or recipient ecknowledges the U.S. Government'a right to retein e nonexclusive, rovalty-free license in and to any copyright covering the orticle.
This report was prepared as an account of work sponsored by an agency of the United States Government. Neither the United States Government nor any agency thereof, nor any of their employees, makes any warranty, express or implied, or assumes any legal liability or responsibility for the accuracy, completeness, or usefulness of any information, apparatus, product, or process disclosed, or represents that its use would not infringe privately owned rights. Reference herein to any specific commercial product, process, or service by trade name, trademark, manufacturer, or otherwise does not necessarily constitute or imply its endorsement, reconmendation, or favoring by the United States Government or any agency thereof. The views and opinions of authors expressed herein do not necessarily state or reflect those of the United States Government or any agency thereof. 


\section{Introduction}

Negative ions are of considerable current interest for both theoretical and practical reasons. We have developed an experimental technique - fast-beam autodetachment spectroscopy - which permits us to investigate the structure of metastable negative ions. These ions are formed when an electron attaches itself to an atom or molecule in a metastable excited state to form a configuration in which the spins of all the active electrons are aligned. Such spin-aligned states are metastable against autodetachment and if they are the lowest-lying state of a given multipilicity they are also metastable against radiative decay. Eventually, such states relax via forbidden autodetachment processes with lifetimes typically $-10^{-6}$ to $10^{-4} \mathrm{~s}$. In this paper we review some of our recent measurements on metastable $\mathrm{Be}^{-}$and $\mathrm{He}_{2}^{-}$ions $[1,2]$.

The source of the metastable negative ions studied using this experimental technique is a fast moving and unidirectional beam produced by charge-changing a beam of momentum selected positive ions in an alkali vapor cell. The metastable spin-aligned state is formed following the sequential capture of two electrons. The $(1 \mathrm{~s} 2 \mathrm{~s} 2 \mathrm{p})^{4} \mathrm{P}$ state of $\mathrm{He}^{-}$is perhaps the most familiar state of this type. In addition to investigating $\mathrm{He}^{-}\left({ }^{4}\right) \mathrm{P}$, we have successfully produced and studied analogous doublyexcited and spin-aligned states such as the $\left(1 s^{2} 2 s 2 p^{2}\right)^{4} \mathrm{P}$ [4] state in the atomic ion, $\mathrm{Be}^{-}$, and the $\left(1 \mathrm{~s} \sigma_{\mathrm{g}}^{2} 1 \mathrm{~s} \sigma_{\mathrm{u}} 2 \mathrm{~s} \sigma_{\mathrm{g}}^{2} 2 \mathrm{p} \pi_{\mathrm{u}}\right)^{4} \Pi_{\mathrm{g}}$ state in the molecular ion, $\mathrm{He}_{2}^{-}$by the use of the method of fast beam autodetachment spectroscopy.

\section{Experimental Arrangement}

The major components of the apparatus are shown in Fig. 1. An accelerator is used to produce a positive ion beam of the desired kinetic energy. The beam energy is chosen to efficiently produce negative ions by a double-electron capture process in a lithium vapor charge-exchange cell through which the positive ion beam is passed following momentum analysis. The different charge state components in the beam emerging from the charge-exchange cell are separated electrostatically and the negative ions are deflected by $10^{\circ}$ into a beam line containing a gas cell, a spherical sector electrostatic energy analyzer, and a shielded Faraday cup. The spatial separation between the charge-exchange cell and the electron spectrometer corresponded, at the beam energies used in these measurements, to a time delay of a few microseconds between the production of the metastable negative ion state and the detection of electrons from the autodetaching decay of the state. This arrangement 
ensures that we are studying only those states that are metastable against both autodetachment and radiative decay. The gas cell is used to produce, when needed, a high-pressure region just in front of the spectrometer for the purpose of collisionally stripping electrons from the negative ion beam. The electron signal from the energy analyzer is stored in a CAMAC-based multichannel scalar data acquisition system. Three pairs of mutually perpendicular Helmholtz coils are used to reduce stray magnetic fields in the vicinity of the electron spectrometer.

\section{Kinematics}

Electrons ejected in the forward direction following autodetachment or collisional detachment of the fast moving negative ions are energy analyzed by the electron spectrometer. The energy of these electrons, as measured in the laboratory reference frame $\left(E_{L}\right)$, is related to the corresponding energy in the particle reference frame $\left(E_{c}\right)$ by the well known kinematic equation:

$$
E_{l}=\lambda E_{i} \pm 2\left[\lambda E_{i} E_{c}\right]^{1 / 2}+E_{c}
$$

where $\lambda=\mathrm{m}_{\mathrm{e}} / \mathrm{m}_{\mathrm{i}}$ is the ratio of the electron and ion masses and $E_{\mathrm{j}}$ is the energy of the ion beam. The \pm sign corresponds to electrons being ejected in the forward and backward directions in the particle reference frame. These electrons are separated in energy in the laboratory reference frame by:

$$
\Delta E=4\left(\lambda_{i} E_{i} E_{c}\right)^{1 / 2}
$$

Collisionally-detached electrons have an energy distribution which is sharply peaked at zero energy in the rest frame of the particle and therefore travel at the ion beam velocity in the laboratory frame. In this case only the first term in Eq. (1) survives. The position of this collisional detachment peak, whenever it appears in the electron spectra, can therefore be used as a reference energy for the determination of the energies of peaks associated with autodetachment. It can be shown that:

$$
E_{c}=\left[\left(E_{L}\right)^{1 / 2}-\left(\lambda E_{i}\right)^{1 / 2}\right]^{2} \text {. }
$$

The use of this procedure to determine the energy of an autodetachment peak in the same spectrum, reduces errors associated with contact and surface potentials and the need for precise knowledge of the spectrometer constant. 


\section{Results}

We have used the fast beam autodetachment spectroscopy technique to measure the energy level of the metastable negative ion, $\mathrm{Be}^{-}$. Figure 2 shows a typical electron energy spectrum obtained using a $55 \mathrm{keV}$ beam of $\mathrm{Be}^{-}$ions. The very low energy electron background peak is attributable to electrons generated by ion impact with apertures and other surfaces. The collisional detachment referince peak can be introduced into the spectrum by adding a gas such as argon to the gas cell. From these measurements we determined the energy of the autodetachsd electrons from the spontaneous decay of the $\left(1 \mathrm{~s}^{2} 2 \mathrm{~s} 2 \mathrm{p}^{2}\right)^{4} \mathrm{P}$ state to be $2.53 \pm 0.09 \mathrm{eV}$ in the rest frame of the particles. Figure 3 shows an energy level diagram for $\mathrm{Be}^{-}$and $\mathrm{Be}^{-}$. It can be seen from this figure that the autodetached electrons carry off an energy equal to the difference in energies of the $\left(1 s^{2} 2 s 2 \mathrm{p}^{2}\right)^{4} \mathrm{P}$ state of $\mathrm{Be}^{-}$and the $\left(1 s^{2} 2 s^{2}\right)^{1} \mathrm{~S}$ state of $\mathrm{Be}$. From our measurement of this energy and tabulated data [3] on the excitation energy of the $\left(1 s^{2} 2 s 2 p\right)^{3} \mathrm{P}$ state of $\mathrm{Be}$, we were able to calculate the electron affinity of the Be atom in the $\left(1 \mathrm{~s}^{2} 2 \mathrm{~s} 2 \mathrm{p}\right)^{3} \mathrm{P}$ state. Our value of $195 \pm 90 \mathrm{meV}$ is in good agreement with recent [5] caiculations.

We have also applied the fast-beam method to the study of a metastable molecular negative ion, $\mathrm{He}_{2}^{-}$. Evidence for the existence of this ion was first reported by Bae et al. [6]. Subsequently, Michels [7] calculated the theoretically expected structure of this ion. We have made the first experimental determination of the structure of $\mathrm{He}_{2}^{-}$. [2] The metastable $\mathrm{He}_{2}^{-}$ions were formed in the spin-aligned ${ }^{4} \Pi_{\mathrm{g}}$ state following double-electron capture collisions by $\mathrm{He}_{2}^{+}$ions passing through a lithium vapor cell. Figure 4 shows a spectrum for ${ }^{4} \mathrm{He}_{2}^{-}$obtained with an ion beam energy of $60 \mathrm{keV}$. Two distinct features are seen in the spectrum (see also Ref. 2 for details). A low energy peak, which is actually a doublet, is present as a result of electrons being ejected ir both the forward and backward directions in the particle frame. In this reference frame the energy of these electrons is found to be $11.5 \mathrm{meV}$ and $37.5 \mathrm{meV}$ for ${ }^{4} \mathrm{He}_{2}^{-}$and ${ }^{3} \mathrm{He}_{2}^{-}$, respectively. Based on the calculations of Michels [7], it appears that these electrons are due to vibrational autodetachment. The $v=1$ vibrational level of the $\mathrm{He}_{2}^{-}\left({ }^{4} \Pi_{\mathrm{g}}\right)$ state lies just above the $\mathrm{v}=0$ vibrational level of the $\mathrm{He}_{2}\left(\mathrm{a}^{3} \Sigma_{\mathrm{u}}^{+}\right)$state making autodetachment energetically possible. Using data from both ${ }^{3} \mathrm{He}$ and ${ }^{4} \mathrm{He}$ isotopes we have been able to determine the spacings of the vibrational levels of $\mathrm{He}_{2}^{-}\left({ }^{4} \Pi_{\mathrm{B}}\right)$ state and the electron affinity of the $\mathrm{He}_{2}\left(\mathrm{a}^{3} \Sigma_{u}^{+}\right)$state (see 
Fig. 5). The measured electron affinity value of $175 \pm 30 \mathrm{meV}$ for ${ }^{4} \mathrm{He}_{2}$ is in $\mathrm{good}$ agreement with the recent calculated value [7]. In addition, we have determined an electron affinity of $178 \pm 40 \mathrm{meV}$ for the ${ }^{3} \mathrm{He}_{2}$ isotope.

The higher energy electron peak observed in the spectrum of Fig. 4 is much broader than the energy resolution of the electron spectrometer. The energy of the center of this peak, as measured in the particle frame, is $15.78 \pm 0.13 \mathrm{eV}$. We attribute this peak to an autodetachment process in which the metastable $\mathrm{He}_{2}^{-}\left({ }^{4} \Pi_{\mathrm{g}}\right)$ ion ejects an electron leaving the residual $\mathrm{He}_{2}$ molecule in the repulsive ground state which, in turn, rapidly dissociates into two ground state helium atoms. The peak energy of the higher energy group of electrons seen in our spectra corresponds to the calculated [7] energy difference between the $v=0$ vibrational level of the $\mathrm{He}_{2}^{-}\left({ }^{4} \Pi_{g}\right)$ state and the repulsive potential energy curve of the $\mathrm{He}_{2}\left(\mathrm{X}^{1} \Sigma_{\mathrm{g}}^{+}\right)$ground state at an equilibrium internuclear separation of $1.06 \dot{A}$. The spread in electron energies is a result of the fact that autodetachment can occur, with varying probability, at different internuclear separations within the range $\sim 0.92$ to $1.10 \AA$. Deconvolution of the background-corrected electron spectra with the instrumental resolution function and the use of the known probability distribution functions for the various vibrational levels that are populated permits one to determine the shape of the potential energy curve for the repulsive $\mathrm{He}_{2}\left(\mathrm{X}^{1} \Sigma_{\mathrm{g}}^{+}\right)$state over the range of internuclear separations from 0.92 to $1.10 \dot{\mathrm{A}}$. To our knowledge, our measurements represent the first attempt to use an electron spectroscopic method to investigate the fundamental interaction between two ground state helium atoms.

\section{Acknowledgments}

One of us (TJK) acknowledges postdoctoral support from the U.S. Office of Naval Research (Contract No. ONR 393-071) through the Postgraduate Research Training Program at the Oak Ridge Associated Universities; two of us (DJP and JST) acknowledge support from the U.S. Department of Energy, Division of Chemical Sciences (DE-FG05-85ER13456) through the University of Tennessee; and RNC acknowledges support from the Office of Health and Environmental Research, U.S. Department of Energy. Oak Ridge National Laboratory is operated by Martin Marietta Energy Systems, Inc. under contract DE-AC05-84OR21400 with the U.S. Department of Fnergy. 


\section{References}

(1) T. J. Kvale, G. D. Alton, R. N. Compton, D. J. Pegg, and J. S. Thompson, Phys. Rev. Lett. 55 (1985) 484.

(2) T. J. Kvale, R. N. Compton, G. D. Alton, J. S. Thompson, and D. J. Pegg, Phys. Rev. Lett. 56 (1986) 592.

(3) Atomic Energy Levels I (S. Bashkin and J. O. Stoner, Eds.), North-Holland, Amsterdam, 1975.

(4) D. R. Beck and C. A. Nicolaides, Inst. J. Quantum Chem. 18 (1984) 467.

(5) A. V. Bunge, Phys. Rev. 33 (1986) 82.

(6) Y. K. Bae and J. R. Peterson, Phys. Rev. A 30 (1984) 2145.

(7) H. H. Michels, Chem. Phys. Lett. 126 (1986) 537. 


\section{Figure Captions}

Fig. 1. Schematic of the apparatus.

Fig. 2. Electron energy spectra from $55 \mathrm{keV} \mathrm{Be}-$ ions with and without a thin argon target placed in front of the spectrometer.

Fig. 3. Energy level diagram of $\mathrm{Be}^{-}$.

Fig. 4. Electron autodetachment spectrum from $60 \mathrm{keV}{ }^{4} \mathrm{He}_{2}^{-}$ions. The structure in the low-energy peak is real and results from forward-backward vibrational autodetachment.

Fig. 5. Potential energy curves showing $\mathrm{He}_{2}\left(\mathrm{a}^{3} \Sigma_{\mathfrak{u}}^{+}\right)$and $\mathrm{He}_{2}^{-}\left({ }^{4} \Pi_{\mathrm{g}}\right)$. 
EXPERIMENTAL APPARATUS FOR MEASURING SHORT HALF LIFE METASTABLE NEGATIVE IONS

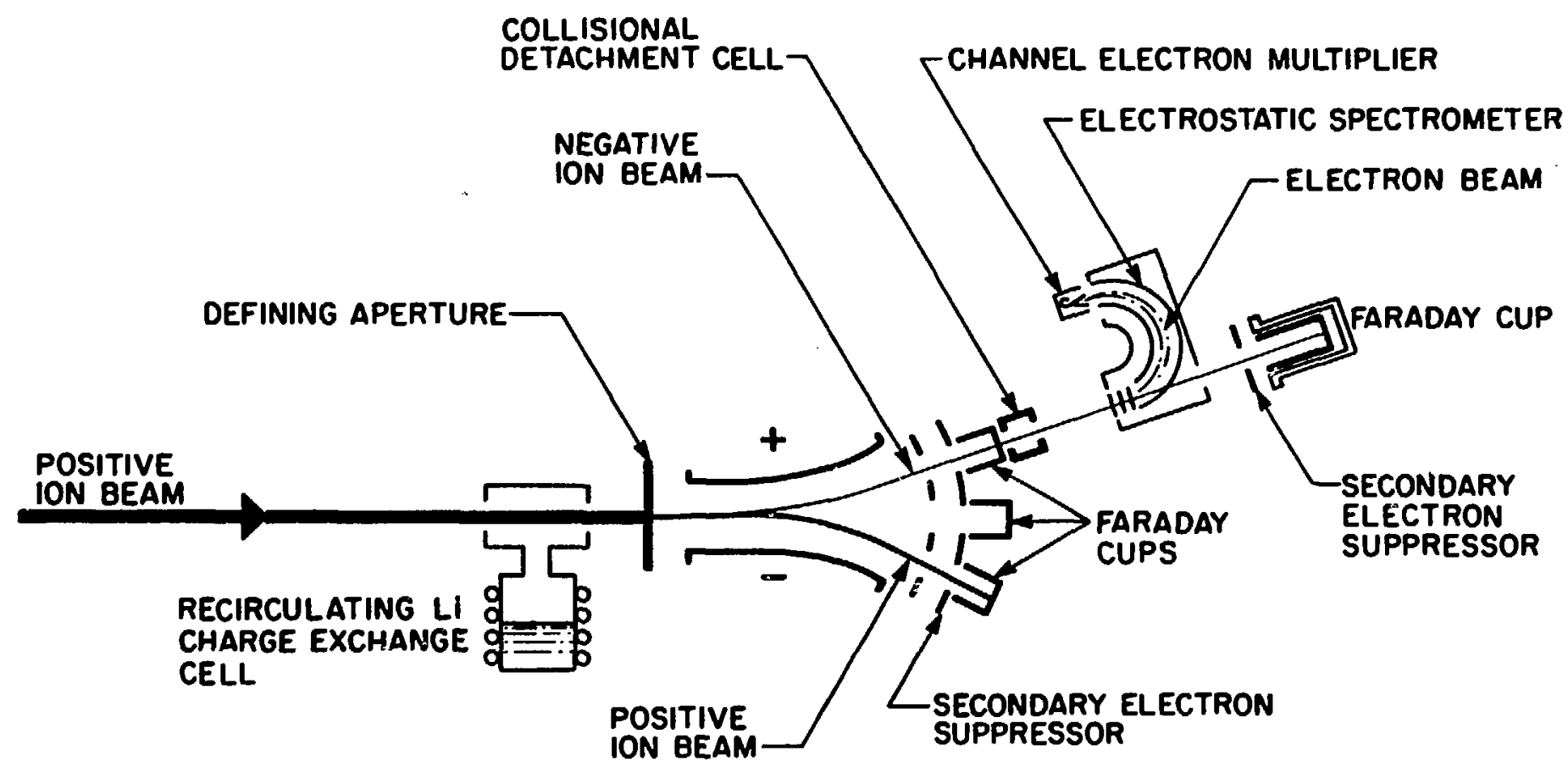




\section{$\mathrm{Be}^{-} \quad 55 \mathrm{keV}$}

Electron Energy Spectra

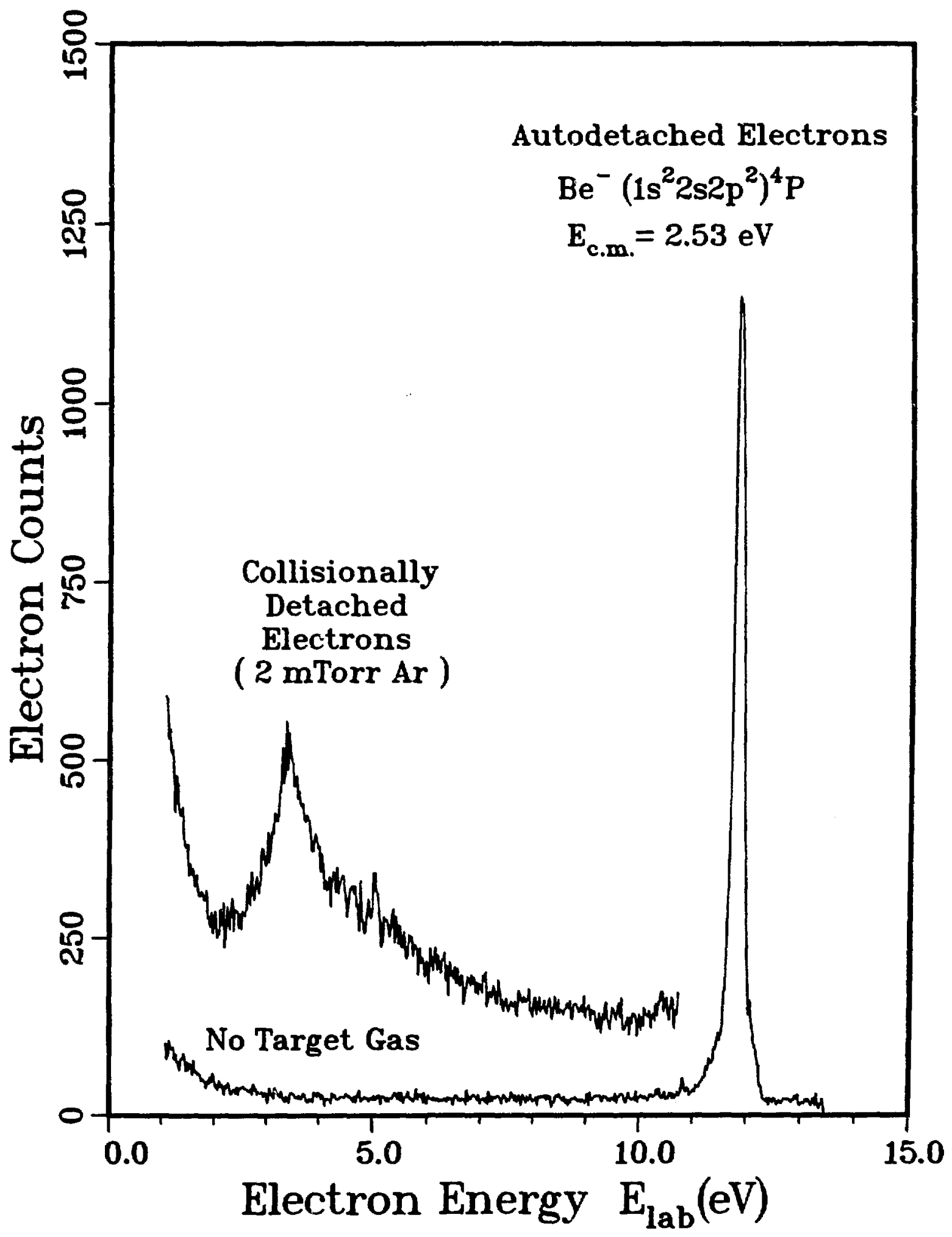


ORNL-DWG 85.10060R

Energy

(eV)

- $\left(1 \mathrm{~s}^{2} 2 \mathrm{~s} 3 \mathrm{~s}\right)^{3} \mathrm{~s}$ -

6.00

5.00

$\left(1 s^{2} 2 s 2 p\right)^{1} p^{0}$

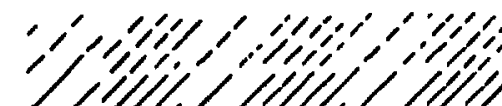

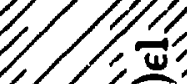




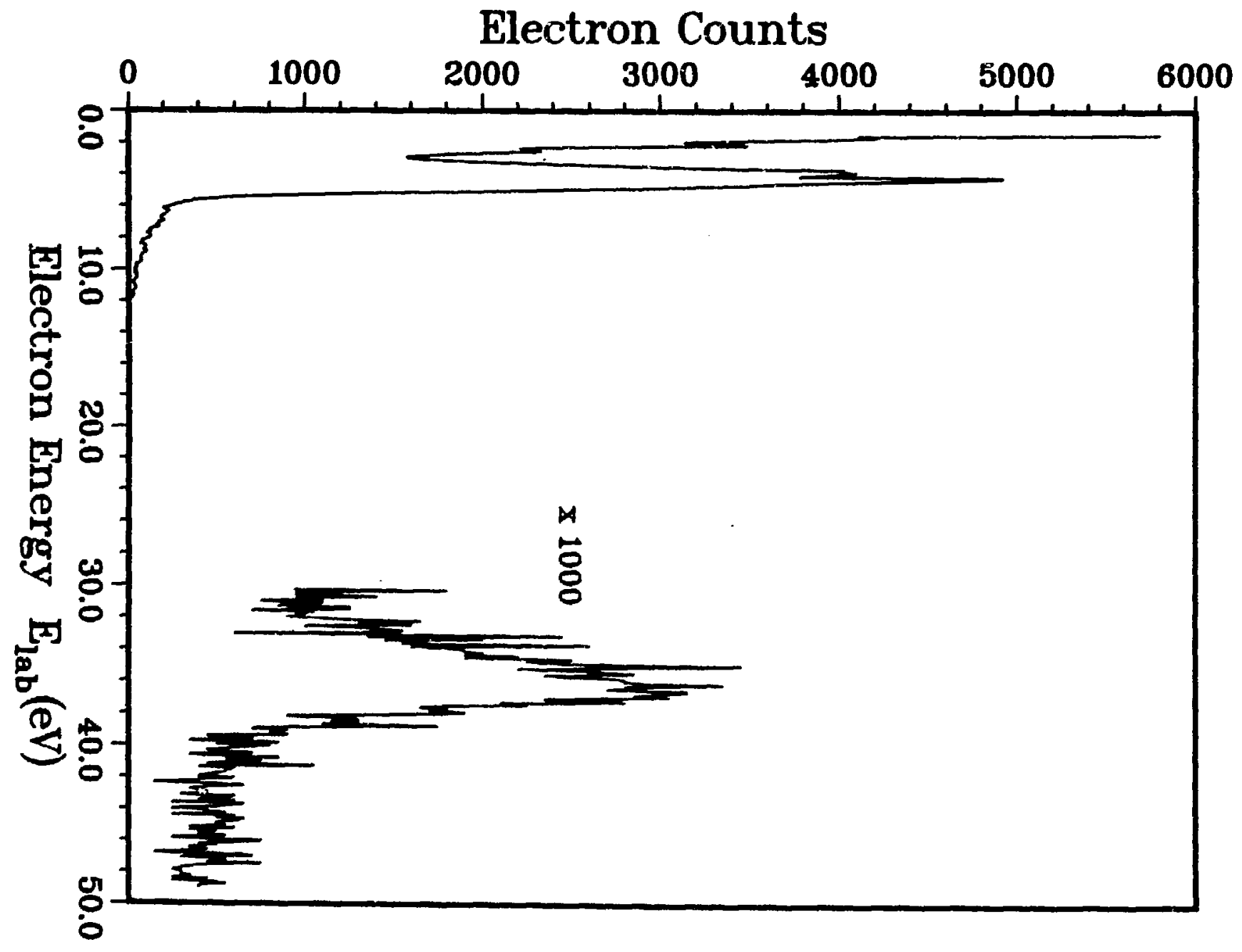

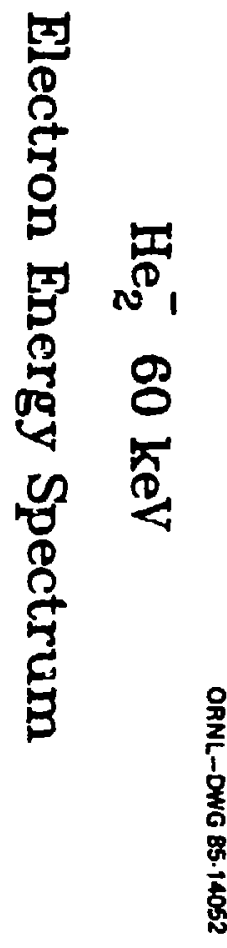


$\mathrm{He}_{2}$

Potential Energy Curves

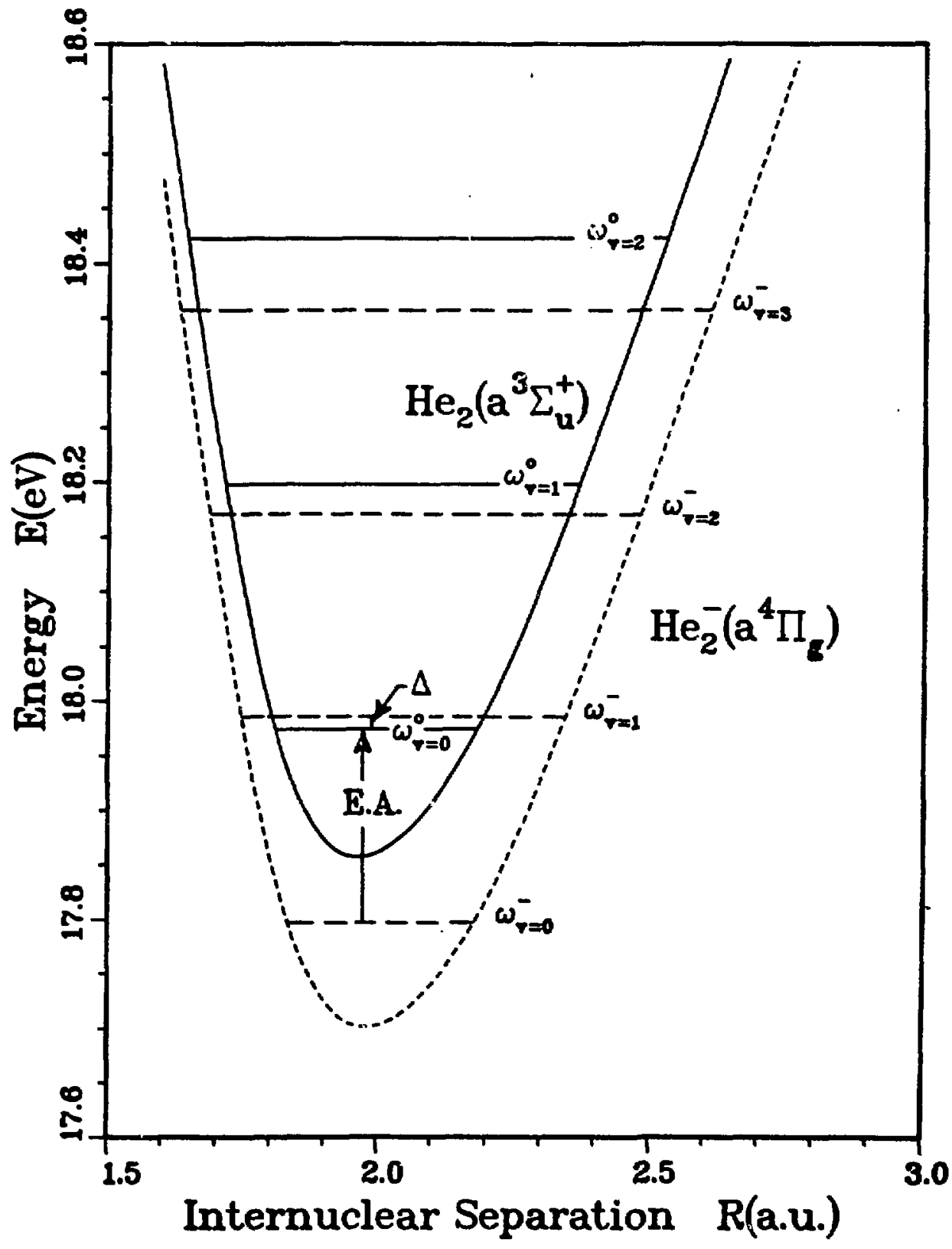

